The information needs of partners and family members of cancer patients: a systematic literature review

\title{
Eike Adams
}

Oxford Brookes University

School of Health and Social Care

Jack Straws Lane

Marston

Oxford OX3 0FL

Phone: 08165485278

Fax: 01865485297

eadams@brookes.ac.uk

\section{Mary Boulton}

Oxford Brookes University

School of Health and Social Care

\section{Eila Watson}

Oxford Brookes University

School of Health and Social Care 


\begin{abstract}
Objective

This review examined the extent to which the information needs of partners and family members of cancer patients have been addressed in the literature.
\end{abstract}

\title{
Methods
}

We conducted a systematic search of 4 databases for papers published between 1998 and 2008 which assessed the information needs of partners and/or family members of adult cancer patients.

\section{Results}

Thirty-two papers were included in the review. Eleven categories of information need were identified. There was a predominant focus on breast or prostate cancer, leaving a knowledge gap in relation to other cancers. Few papers moved beyond the diagnosis and initial treatment phase, and most did not distinguish between met and unmet needs. Those that did, indicated that partners/family members are more likely to have unmet needs for information about supportive care than for medical information. The concept of 'information need' was generally poorly developed and theorised in the papers.

\section{Conclusion}

Establishing the information needs of partners and family members of cancer patients is an important, but as yet neglected, area of research. In order to develop our understanding of this area more empirical research, with sound conceptual and theoretical foundations is required. 


\section{Introduction}

It is estimated that there are currently over 24 million people worldwide living with cancer (1), with 2 million in the UK alone (2). Providing information to cancer patients has been shown to relieve anxiety and improve psychological wellbeing (3-5). It can also empower patients and help them make informed treatment decisions $(6,7)$. In England the recent Cancer Reform Strategy (8) has highlighted information provision as one of its key priorities, as has the President's Cancer Panel 2006 report in the USA (9). In the current policy context where patient choice, shared decision-making and self-care have gained prominence and where a shift in emphasis from compliance to concordance can be observed, information on which to base choices and decisions is increasingly recognised as important (10-12).

Cancer organisations internationally are now emphasising the importance of partners and family members in patients' cancer experiences. It has been reported that family members experience similar levels of distress to cancer patients themselves following diagnosis (12). As medical advances have prolonged life and facilitated the treatment of patients in outpatient and community settings, partners and family members have also become more involved in the care of cancer patients, both physically and emotionally $(13,14)$.

Furthermore, decisions about treatment and care are often not made by individuals with cancer alone, but are socioculturally, situationally and interpersonally contingent, and made in the context of family and friendship networks (12). Partners and family members may play a significant role in decision making and to facilitate informed choices for the patient's benefit, their information needs must also be addressed. 
Previous reviews that have addressed the information needs of family members of cancer patients have indicated that family members are dissatisfied with the cancer-related information they have received and need further information to help them deal with the impact of cancer $(15,16)$. However, these reviews have considered family members' and patients needs together, and they have tended not to synthesise their findings. Three studies $(5,17,18)$ were cancer-site specific, and one (17) was on satisfaction with information, rather than information needs per se. The last comprehensive review of information needs including a number of cancers was in 1998.

This paper provides a systematic review of the literature on information needs of partners and family members of cancer patients from 1998 to 2008. Our aims in conducting the review were to describe 1) the substantive areas of information need identified in the literature to date; 2) the information needs which are specific to particular family relationships; 3) the information needs which are specific to particular cancer sites; 4) changes in information needs over the course of the cancer trajectory; and 5) met and unmet information needs. Such an overview is fundamental to assessing what is known about information needs of partners and family members of cancer patients and to identifying where further research is needed.

\section{Methods}

A systematic search of MEDLINE, PsychINFO, the Cumulative Index to Nursing and Allied Health Literature (CINAHL), and the Institute for Scientific Information (ISI; Social Science Citation Index and Web of Science) was undertaken. To be comprehensive, the 
search strategy included searches with both thesaurus and free terms, such as "neoplasm" and "tumour/tumor" in conjunction with "information need" and various terms for "family member" (see Appendix A for an example of a search strategy). The search was limited to papers written in English and published between January 1, 1998 and June 30, 2008. Only studies where the cancer patient was an adult were included although family members of cancer patients could include children or adolescents. This resulted in 2,359 citations of potential relevance. All abstracts were reviewed by one researcher (EA) who identified 92 papers as potentially relevant. Each of these was reviewed by at least two of the three researchers, with disagreements resolved by all three. Papers were excluded where: 1) the majority of patients were in the terminal stage or had metastatic disease; 2) they focused on information needs of patients or did not distinguish clearly between the needs of patients and family members; 3) they focused on sources of information; 4) they focused on ways of providing or delivering information; 5) they reported interventions to meet information needs; or 6) they focused on methodological issues only (e.g. the development of a research instrument). In total, 32 papers were included in the review. Two papers reporting the same study were included as they matched the inclusion criteria and reported substantially different findings in each paper.

Studies were classified according to the relationship of the participants to the patient with cancer, as studies of partner/spouse, child, or mixed. 'Child' was here defined as schoolaged or adolescent, and distinguished from adult children. No studies with only other family members (e.g. siblings, parents, adult children) were found. Participants in studies classified as 'mixed' included partners, spouses, children and other family members. 
Stages in the patients' cancer trajectory were identified from the descriptions of study design reported in the papers. A distinction was made between the stage of the patients' cancer trajectory at the time of data collection and the stage which was the focus of the study.

Papers which reported studies that restricted recruitment to partners and family members of patients with a particular cancer were classified according to the cancer site of interest; the remainder were classified as mixed site studies.

The information needs reported in the papers were coded and grouped into categories based on a classification scheme developed by Rutten et al. (18). Codes and categories were developed from the information needs items reported in the papers using a 'bottom-up' approach, and were redefined and refined throughout the review process. All 32 papers were read several times to enable rigorous coding of information needs. The coded information needs were then discussed by the three researchers and combined into relatively narrow sub-categories which were then grouped into broader main categories. The number and percent of papers in which each main category of information need was reported were calculated to indicate their relative frequency.

Where papers reported information needs as 'met' or 'unmet', this distinction was carried forward as a dimension of the coded and categorised needs described in this paper. 


\section{Results}

\subsection{Characteristics of the studies reported in the literature}

Characteristics of the studies described in the papers are summarised in Table 1. The great majority of studies examined information needs of partners or spouses: almost half the studies looked exclusively at partners or spouses and in studies with mixed samples, the majority were partners or spouses. A large proportion of the studies were conducted with partners or family members of patients with breast cancer or prostate cancer. Samples were drawn from across the cancer trajectory in terms of the patient's treatment stage at the time of interview, but the majority of studies nonetheless concentrated on information needs in the early stages of diagnosis and active treatment. Most studies were cross sectional in design and used quantitative or mixed methods of data collection and analysis.

Table 1. Sample characteristics ( $\mathrm{n}=32$ articles)

\begin{tabular}{|c|c|c|}
\hline Characteristics & $\mathbf{N}$ & $\%^{1}$ \\
\hline \multicolumn{3}{|l|}{ Relationship to patient } \\
\hline Spouse/partner & 14 & 43.8 \\
\hline Children & 4 & 12.5 \\
\hline Mixed relationships & 14 & 43.8 \\
\hline \multicolumn{3}{|l|}{ Cancer sites } \\
\hline Breast & 12 & 37.5 \\
\hline Prostate & 7 & 21.9 \\
\hline Brain & 2 & 6.3 \\
\hline Colon & 1 & 3.1 \\
\hline Oesophageal & 1 & 3.1 \\
\hline Multiple sites & 7 & 21.9 \\
\hline Not specified & 2 & 6.3 \\
\hline \multicolumn{3}{|l|}{ Sample country } \\
\hline Canada & 10 & 31.3 \\
\hline US & 7 & 21.9 \\
\hline UK & 6 & 18.8 \\
\hline Australia & 3 & 9.4 \\
\hline
\end{tabular}

\footnotetext{
${ }^{1}$ Rounded to the nearest full number.
} 


\begin{tabular}{|c|c|c|}
\hline Finland & 2 & 6.3 \\
\hline Japan & 1 & 3.1 \\
\hline Turkey & 1 & 3.1 \\
\hline Sweden & 1 & 3.1 \\
\hline Greece & 1 & 3.1 \\
\hline \multicolumn{3}{|c|}{ Cancer continuum phase - stage of patient at time of recruitment } \\
\hline Diagnosis/treatment & 14 & 43.8 \\
\hline Post-treatment/survivorship & 2 & 6.3 \\
\hline Multiple specific stages & 13 & 40.6 \\
\hline Not specified & 3 & 9.4 \\
\hline \multicolumn{3}{|l|}{ Cancer continuum phase - focus of study } \\
\hline Diagnosis/treatment & 23 & 71.9 \\
\hline Multiple specific stages & 4 & 12.5 \\
\hline Stages not specified & 5 & 15.6 \\
\hline \multicolumn{3}{|l|}{ Publication date } \\
\hline $1998-2002$ & 15 & 46.9 \\
\hline 2003- April2008 & 17 & 53.1 \\
\hline \multicolumn{3}{|l|}{ Overall study design } \\
\hline Concurrent & 16 & 50.0 \\
\hline Retrospective & 7 & 21.9 \\
\hline Prospective/longitudinal & 2 & 6.3 \\
\hline $\begin{array}{l}\text { Other (retrospective/ concurrent: 6; longitudinal/ } \\
\text { concurrent: 1) }\end{array}$ & 7 & 21.9 \\
\hline Quantitative (questionnaire/survey) & 15 & 46.9 \\
\hline Validated $\mathrm{Q}^{2}$ & 7 & 21.9 \\
\hline Study-specific Q & 6 & 18.8 \\
\hline $\begin{array}{l}\text { Other (content analysis of helpline/message } \\
\text { boards) }\end{array}$ & 2 & 6.3 \\
\hline Qualitative & 11 & 31.3 \\
\hline Interviews & 7 & 21.9 \\
\hline Focus groups & 1 & 3.1 \\
\hline Interview + focus groups & 2 & 6.3 \\
\hline Questionnaire (with open-ended questions) & 1 & 3.1 \\
\hline Mixed methods & 6 & 15.6 \\
\hline Validated Q+ Interview + focus groups & 1 & 3.1 \\
\hline Validated Q+ interview/ open-ended questions & 3 & 9.4 \\
\hline Study-specific Q + interview & 2 & \\
\hline \multicolumn{3}{|l|}{ Sample size } \\
\hline Quantitative studies & $\mathrm{Ra}$ & \\
\hline
\end{tabular}

${ }^{2}$ This denotes the method by which information about information needs specifically was collected, not the data collection method overall. 


\begin{tabular}{|l|l|l|}
\hline & 26,789 & \\
\hline$>30$ & $5^{3}$ & \\
\hline $30-100$ & 9 & \\
\hline$>100$ & 3 & \\
\hline Qualitative studies & Range 9-31 & \\
\hline$<15$ & 3 & \\
\hline $15-40$ & 8 & \\
\hline$>40$ & 0 & \\
\hline Mixed methods studies & Range $15-$ & \\
& 195 & \\
\hline$<30$ & 1 & \\
\hline $30-100$ & 5 & \\
\hline$>100$ & 1 & \\
\hline
\end{tabular}

\subsection{Information needs of partners and family members}

The information needs reported in the papers were coded and grouped into 11 main categories and 56 subcategories. Table 2 presents the categories of information needs in descending order of frequency with which they were reported in the papers. Treatmentrelated information and diagnosis-related information were the most frequently mentioned (in $91 \%$ and $81 \%$ of papers respectively); information on hospital care and followup/rehabilitation information were the least frequently mentioned (in $28 \%$ and $16 \%$ of papers respectively).

\footnotetext{
${ }^{3}$ Two studies had two groups of participants. Each of these was here included as a separate group of participants, hence the total number of studies in this section is greater than the actual number of studies.
} 
Table 2. Typology of the information needs of partners and family members of cancer patients $(\mathrm{n}=32$ articles $)$

Quantitative articles $=$ normal font

Qualitative articles $=$ underlined font

Mixed methods articles $=$ bold font

\subsubsection{Relationship-specific information needs}

Fourteen of the 32 studies reviewed focused exclusively on partners or spouses of cancer patients $(6,19-31)$. Information needs regarding intimacy, sexuality and sexual functioning were reported almost exclusively by this group. Sexuality and sexual functioning were discussed by 9 of the 14 studies $(6,19-22,25-28)$. Information needs regarding intimacy were reported in four studies, all of which used the Family Inventory of Needs $(6,26-28$, 32).

Four of the 12 'mixed' studies which predominantly included partners and spouses also discussed sexuality and sexual functioning (32-36), but they did not relate any particular needs to particular subgroups of participants in the study. Interestingly, in one additional 'mixed' study (34) adult daughters of the patient rated the need for information about the patient's sexual attractiveness as more important than did patients' spouses.

Four studies were conducted with school-aged or adolescent children of cancer patients (37-40). No specific information needs were identified for this group. 


\subsubsection{Cancer site-specific information needs}

The majority of papers reported single cancer site studies. Comparisons across these papers identified a number of information needs which were reported predominantly by partners and family members of patients with particular cancers. In breast cancer studies, these included information on treatment options $(25,34,38)$, complementary/alternative therapies $(25,34,39-41)$, understanding trials $(34)$, chances of survival $(23,38,39)$, causes and risk factors (34, 38-40), incidence rates (38), and impact on everyday life (31). Amongst partners and families of patients with prostate cancer, these needs included information on incontinence $(20,22,24)$, catheter care $(20,24)$ and sexuality $(6,20-22,24$, $27,28)$. Studies on brain tumours were the only ones to report a need for information on reasons for a delay in diagnosis, the availability of care services, and hospital operational procedures (42) as well as practical information regarding legal services and settling affairs/ writing a will (43).

Two mixed site studies $(44,45)$ investigated the relationship between the patients' cancer sites and the information needs of their partners and family members but neither found a statistically significant relationship.

\subsubsection{Information needs across the cancer trajectory}

The majority of studies took the early stages of diagnosis and active treatment as their sole focus of attention. This was the case in 24 studies (of which 14 recruited only partners and family members of recently diagnosed patients or those in active treatment, and 10 recruited partners or family members at a variety of stages but only explored the diagnosis and treatment stages). These studies identified treatment-related information and prognosis- 
related information as most important, followed by coping information and information on self-care/homecare $(7,19-22,24-36,38,39,41,42,44,46)$.

In our sample, of 13 studies that included family members of cancer patients at different stages of the cancer trajectory $(6,23,25,29-31,36-38,40,42,43,45)$ only three examined information needs by stage in the cancer trajectory, and then only cross-sectionally $(40,43$, 45). In relation to the initial diagnosis/treatment stage, these studies also identified treatment-related information and diagnosis/ prognosis-related information as most important (45), as well as information on possible emotional reactions (of the patient and partner or family member) and information on how to access and give emotional support $(43,45)$. In relation to the post-treatment/ survivorship stages, these studies reported information needs as including general lifestyle changes and social re-entry (43), rehabilitation and long-term care (40), late effects of treatment (45) and recurrences or metastases (45). No studies focused exclusively on the post-treatment/survivorship stages.

\subsubsection{Met and unmet needs}

Seven of the 15 quantitative studies distinguished between information needs that were met and those which were unmet. Table 3 presents unmet needs in descending order of frequency. The most frequently unmet needs were diagnosis-/prognosis-related information, information about the impact on the family, information about the impact on the relationship with the partner, information on practical issues, coping information, and treatment-related information. 
The distinction between met and unmet needs in the interview-based studies was less clearcut. However, three of these studies reported unmet information needs which were consistent with the need for information discussed in the questionnaire-based studies. For instance, more prognosis- and survival-related information was wished for $(37,38)$, and one study discussed information about side effects, will/power of attorney, and financial issues as 'major themes' (43).

\section{Discussion and conclusion}

\subsection{Discussion}

This paper has presented the findings of a systematic review of the literature on information needs of partners and family members of cancer patients. The review has restricted its focus to papers specifically on information needs, excluding papers on how information was delivered or conveyed and intervention studies which described attempts to meet information needs. Such studies may nonetheless make a significant contribution to our understanding of the information needs of partners and family members of cancer patients and the findings of this study should be seen in this wider context.

We conducted a systematic search of four major data bases but found only a relatively small number of studies -32- which reported the information needs of partners and family members of cancer patients. This contrasts with the much larger number of studies of the information needs of cancer patients, where a recent review (18) identified 112 papers. 
The studies included in our review provide further evidence that a diagnosis of cancer has a significant impact on the partners and family members of patients, and that they perceive a need for information on a wide range of topics. Eleven main categories of information need and 56 sub-categories were distinguished from the findings of the 32 studies included in the review. These findings need to be interpreted with caution, however, as the categories of need identified and the frequency with which they were reported are products of the way the studies included in this review collected their data. For example, studies which used lengthy questionnaires (e.g. the Family Inventory of Need $(6,26-28,32)$ or the Psychosocial Needs Inventory (45)) were likely to report a larger number of sub-categories of information needs than studies which used short questionnaires or qualitative studies which conceptualised needs in broader terms. Similarly, where the same questionnaire (eg the Family Inventory of Need) was used in a number of studies, the needs it asked about were likely to be reported with greater frequency.

Some information needs were identified more commonly amongst particular groups. Studies of partners or spouses of cancer patients were, not surprisingly, substantially more likely to identify information needs around intimacy and sexuality. Studies of partners or spouses of prostate cancer patients were more likely to report needs for information on incontinence and catheter care, while those of partners or spouses of breast cancer patients were more likely to report needs for information on complementary/alternative therapies, understanding trials, chances of survival, causes and risk factors and impact on everyday life. However, caution is again needed in interpreting these findings as the questions asked in these studies may reflect the researchers' assumptions of what are likely to be - or not be - the information needs of the population they are studying. 
It is also important to note that the majority of studies focused on the partner or spouse of the cancer patient, rather than other family members. A wider variety of significant others could be examined in future research. This might be particularly pertinent considering the different relevance of family and friendship networks in different cultural groups. Most studies in this review did not discuss the sociocultural specificity of care and information needs. However, papers from a cultural background other than the dominant white AngloAmerican setting did point to cultural differences in the organisation of care, and therefore, potentially, differences in information needs $(35,44)$.

Current research on the information needs of partners and family members of cancer patients focuses predominantly on breast and prostate cancer. Although these are clearly common and important cancers, there is also an urgent need for studies which pay attention to the information needs of the family members of patients with other types of cancer. This is particularly pertinent in the light of a previous finding by Morris and Thomas (47) who reported differences in the level of satisfaction with information provision amongst different groups of carers, with carers of lung cancer patients reporting highest levels of dissatisfaction.

Although a number of previous papers have emphasized that information needs are contingent on the person's stage in the cancer trajectory $(4,17,48,49)$, we found few studies which looked at how information needs changed over the cancer trajectory, or the information needs of partners and families of longer term cancer survivors. Most studies were conducted in the early stages of the patient's cancer trajectory or focused exclusively on this period of diagnosis and active treatment. Almost all were cross-sectional in design. As treatments for cancer improve and individuals live much longer following a cancer 
diagnosis, more research is needed on the information needs of their partners and family members. It has been shown that some stages in the cancer trajectory are particularly anxiety-provoking $(4,17,18)$ and it is likely that information needs will vary at these different stages. For example, it is important that information needs following discharge from initial treatment, following final discharge from hospital follow up, and during the long term survivorship phase are well understood. Longitudinal studies in particular are needed to assess how needs change over time (17), and to inform the development of interventions which take into account the appropriate timing of the information given.

Relatively few studies included in this review distinguished between met and unmet needs. Of the studies which did address this, psychosocial and supportive care information needs were more likely to remain unmet compared with medically-oriented needs. A previous review, which focussed on prostate cancer, reported similar findings (48). These results suggest that there may therefore be a disparity between the current focus of research on information needs around the time of diagnosis and treatment, and the areas in which family members are reporting unmet needs. They also suggest a need for medical practitioners to address psychosocial and supportive care information needs more directly; and for family members to be more involved in setting the research agendas in the area of information needs, so that their (unmet) needs are more directly reflected in those agendas. In the UK, first steps have been taken in this direction by the charity Macmillan Cancer Support, who in their survivorship agenda Two Million Reasons (2) identified family members' needs as a priority.

The information needs identified in this review are broadly similar to those identified in reviews of the needs of cancer patients themselves. For instance, the review by Rutten et al. 
(18) also identified treatment-related information as the most frequently mentioned information need, and rehabilitation information, prognosis information and coping information were also in the top five. However, many of the studies examining information needs in both patients and family members simultaneously have not distinguished between patients' and family members' needs, making comparison and the drawing of any firm conclusions difficult. If the information needs of these two groups are similar, more emphasis could be placed on the involvement of family members when information is given to patients. However, this has implications for current NHS practice where the family member cannot access information from the cancer patient's health professional without the patient's consent (47).

We have identified several methodological limitations which make the interpretation of findings difficult. Despite previous criticisms of the literature on information needs, $(4,17$, $18,48,49)$, recent research in this field continues to be hampered by 1) poor conceptualisation of 'information need' ; (2) the lack of a theoretical or conceptual framework underpinning empirical work; and (3) the use of ad hoc and unvalidated questionnaires in survey research.

While the term 'information need' is used throughout the literature, in the papers we reviewed it was rarely defined or distinguished from related concepts. In a concept analysis, Timmins (50) argued that 'information need' describes an expressed and idiosyncratic need, in contrast to normative needs which are defined by professionals. This conceptualisation does not seem to be widely shared, however, and several papers used normative concepts such as 'education need' or 'learning need' in defining information need $(19,42)$. Greater conceptual clarity is needed in future empirical work to distinguish 
those needs defined by individuals in relation to their own circumstances and those needs defined more generically by a wider range of those involved in cancer care.

Similarly, while a number of the reviewed studies referred to a theoretical framework, only two studies $(21,29)$ used one explicitly in their design. Theoretical frameworks referred to included the Stress and Coping Model by Lazarus and Folkman (51), a supportive care framework $(22,38,43,44)$ and Family Systems Theory $(30,37,40,42)$, all of which provide useful frameworks for investigating aspects of information needs. Future research could be considerably strengthened by using any of these theoretical frameworks to inform research design, development of research instruments (both questionnaires and interview schedules) and interpretation of findings. This would facilitate comparisons across studies needed to build up a coherent body of knowledge on the information needs of partners and family members of cancer patients and provide the foundations for developing interventions to meet their information needs and for assessing their outcomes.

A related shortcoming was the use of ad hoc and unvalidated questionnaires to identify information needs in a number of studies. Fixed-choice questionnaires can constrain the scope for patients to report their information needs and may distort or fail to capture the full range of needs. Qualitative studies allow participants greater opportunity to define their information needs in their own terms but are less likely to explore them in a systematic way. Studies which used detailed questionnaires that had been developed and validated using qualitative methods are in a better position to overcome some of the limitations of both approaches and provide systematic information on patient-defined information needs. However, of 20 studies in our sample using questionnaires, only ten were validated. Five of these were adjusted versions of the Family Inventory of Needs (FIN) (52). Further work is 
needed to develop validated questionnaires for specific groups and cancer sites and a greater emphasis needs to be given to using these in future research.

\subsection{Conclusions}

This review provides an up-to-date overview of the literature on the information needs of families of cancer patients.

The review has confirmed that partners and family members of cancer patients have a wide range of information requirements which need to be addressed. While many of these information needs might be similar to those of the cancer patient, at least around the time of diagnosis and initial treatment, they may also differ in detail and perspective.

In the early stages of the cancer trajectory, not surprisingly, information regarding diagnosis and treatment are most valued. Much less is known about information needs at later stages. With improved treatments and survival rates, a focus on later stages of the cancer trajectory is becoming more pertinent.

Our review has indicated that information on non-medical topics such as coping with cancer, or the impact of cancer on relationships, is more likely to be lacking in partners and family members than medically-oriented information. Further research which distinguishes between met and unmet information needs is required to confirm this finding, and thought given to how to provide this type of supportive care information to patients and their families. 
Future research in the area of information needs would benefit from being more theoretically informed and methodologically robust - with studies using larger sample sizes, validated measures, and longitudinal, mixed-method research designs. Studies are needed which focus on other cancer sites in addition to breast and prostate cancer, on the needs of patients' children, other family members (siblings, adult children of older patients), and the family as a whole.

\subsection{Practice Implications}

Cancer organisations and policy makers are now beginning to emphasize the importance of partners and family members in patients' cancer experiences.

This review underlines the fact that partners and family members have a wide range of information needs. It is therefore important that practitioners recognise these needs alongside those of the patient. Systems which permit the identification of information needs throughout the cancer journey are required.

Strategies should also be developed to ensure best use is made of available resources, for example signposting by health care professionals to good quality written/web-based information. The current implementation of information pathways by the National Cancer Action Team in the UK is one step in this direction (53).

The findings from our study suggest that oncology practice may need to pay greater attention to providing information on non-medical supportive care topics to partners and family members. However, further well-designed research studies are needed to confirm 
these findings and to identify information in a wider range of cancers and throughout the cancer trajectory. 


\section{References}

[1] Cancer Research UK. Cancer worldwide- The global picture. 200820 April 2005 [cited 200822 October]; Available from: http://info.cancerresearchuk.org/cancerstats/geographic/world/

[2] Macmillan Cancer Support. Two million reasons. The cancer survivorship agenda. London: Macmillan Cancer Support; 2008.

[3] Booth K, Beaver K, Kitchener H, O'Neill J, Farrell C. Women's experiences of information, psychological distress and worry after treatment for gynaecological cancer. Patient Educ Couns 2005;56:225-232.

[4] Harris KA. The informational needs of patients with cancer and their families. Cancer Pract 1998;6:39-46.

[5] Ziegler L, Newell R, Stafford N, Lewin R. A literature review of head and neck cancer patients information needs, experiences and views regarding decision-making. Eur J Cancer Care (Engl) 2004;13:119-126.

[6] Rees CE, Sheard CE, Echlin K. The relationship between the information-seeking behaviours and information needs of partners of men with prostate cancer: a pilot study. Patient Educ Couns 2003;49:257-261.

[7] Iconomou G, Vagenakis AG, Kalofonos HP. The informational needs, satisfaction with communication, and psychological status of primary caregivers of cancer patients receiving chemotherapy. Support Care Cancer 2001;9:591-596.

[8] Department of Health. Cancer Reform Strategy. London: Department of Health; 2007.

[9] President's Cancer Panel. Assessing Progress, Advancing Change: 2005-2006 Annual Report. Bethesda, MD: President's Cancer Panel; 2006.

[10] Woolf SH, Chan ECY, Harris R, Sheridan SL, Braddock CH, III, Kaplan RM, et al. Promoting Informed Choice: Transforming Health Care To Dispense Knowledge for Decision Making. Ann Intern Med 2005;143:293300.

[11] Department of Health. The Expert Patient: A New Approach to Chronic Disease Management for the 21st Century. London: Department of Health; 2001. 
[12] Revenson TA, Pranikoff JR. A Contextual Approach to Treatment Decision Making Among Breast Cancer Survivors. Health Psychol 2005;24:S93-S98.

[13] Lewis FM. Strenghtening family supports. Cancer and the family. Cancer 1990;65:752-759.

[14] Kotkamp-Mothes N, Slawinsky D, Hindermann S, Strauss B. Coping and psychological well being in families of elderly cancer patients. Critical Reviews in Oncology/Haematology 2005;55:213-229.

[15] Deeken JF, Taylor KL, Mangan P, Yabroff KR, Ingham JM. Care for the caregivers: a review of self-report instruments developed to measure the burden, needs, and quality of life of informal caregivers. J Pain Symptom Manage 2003;26:922-953.

[16] Kitrungote L, Cohen MZ. Quality of life of family caregivers of patients with cancer: a literature review. Oncol Nurs Forum 2006;33:625-632.

[17] Chapman K, Rush K. Patient and family satisfaction with cancer-related information: a review of the literature. Can Oncol Nurs J 2003;13:107-116.

[18] Rutten LJF, Arora NK, Bakos AD, Aziz N, Rowland J. Information needs and sources of information among cancer patients: a systematic review of research (1980-2003). Patient Educ Couns 2005;57:250-261.

[19] Aucoin-Gallant G. Description of the caregiver's educational needs and the degree of her dissatisfaction. Can Oncol Nurs J 1999;9:171-174.

[20] Butler L, Downe-Wamboldt B, Marsh S, Bell D, Jarvi K. Behind the scenes: partners' perceptions of quality of life post radical prostatectomy. Urol Nurs 2000;20:254-258.

[21] Davison BJ, Gleave ME, Goldenberg SL, Degner LF, Hoffart D, Berkowitz J. Assessing Information and Decision Preferences of Men With Prostate Cancer and Their Partners. Cancer Nurs 2002;25:42-49.

[22] Feldman-Stewart D, Brundage MD, Mackillop WJ. What Questions Do Families of Patients With Early-Stage Prostate Cancer Want Answered? J Fam Nurs 2001;7:188-207.

[23] Fitch MI, Allard M. Perspectives of husbands of women with breast cancer: information needs. Can Oncol Nurs J 2007;17:79-90. 
[24] Giarelli E, McCorkle R, Monturo C. Caring for a Spouse after Prostate Surgery: The Preparedness Needs of Wives. J Fam Nurs 2003;9:453-485.

[25] Hilton BA, Crawford JA, Tarko MA. Men's perspectives on individual and family coping with their wives' breast cancer and chemotherapy. West J Nurs Res 2000;22:438-459.

[26] Kilpatrick MG, Kristjanson LJ, Tataryn DJ, Fraser VH. Information needs of husbands of women with breast cancer. Oncol Nurs Forum 1998;25:131-135.

[27] Mason TM. Information Needs of Wives of Men Following Prostatectomy. Oncol Nurs Forum 2005;32:557563.

[28] Mason TM. Wives of Men With Prostate Cancer Postbrachytherapy. Cancer Nurs 2008;31:32-37.

[29] Northouse LL, Schafer JA, Tipton J, Metivier L. The Concerns of Patients and Spouses After the Diagnosis of Colon Cancer: A Qualitative Analysis. J Wound Ostomy Continence Nurs 1999;26:8-17.

[30] Rees CE, Bath PA, Lloyd-Williams M, Rees CE. The information concerns of spouses of women with breast cancer: patients' and spouses' perspectives. J Adv Nurs 1998;28:1249-1258.

[31] Salminen E, Vire J, Poussa T, Knifsund S. Unmet needs in information flow between breast cancer patients, their spouses, and physicians. Support Care Cancer 2004;12:663-668.

[32] Nikoletti S, Kristjanson LJ, Tataryn D, McPhee I, Burt L. Information Needs and Coping Styles of Primary Family Caregivers of Women Following Breast Cancer Surgery. Oncol Nurs Forum 2003;30:987-996.

[33] Andreassen S, Randers I, Naslund E, Stockeld D, Mattiasson AC. Information needs following a diagnosis of oesophageal cancer; self-perceived information needs of patients and family members compared with the perceptions of healthcare professionals: a pilot study. Eur J Cancer Care (Engl) 2007;16:277-285.

[34] Beaver K, Witham G. Information needs of the informal carers of women treated for breast cancer. Eur J Oncol Nurs 2007;11:16-25.

[35] Gözüm S, Akçay D. Response to the Needs of Turkish Chemotherapy Patients and their Families. Cancer Nurs 2005;28:469-475. 
[36] Grimm PM, Zawacki KL, Mock V, Krumm S, Frink BB. Caregiver Responses and Needs. An Ambulatory Bone Marrow Transplant Model. Cancer Pract 2000;8:120-128.

[37] Chalmers KI, Kristjanson LJ, Woodgate R, Taylor-Brown J, Nelson F, Ramserran S, et al. Perceptions of the role of the school in providing information and support to adolescent children of women with breast cancer. $\mathrm{J}$ Adv Nurs 2000;31:1430-1438.

[38] Fitch MI, Abramson T. Information needs of adolescents when a mother is diagnosed with breast cancer. Can Oncol Nurs J 2007;17:16-25.

[39] Forrest G, Plumb C, Ziebland S, Stein A. Breast cancer in the family--children's perceptions of their mother's cancer and its initial treatment: qualitative study. Br Med J 2006;332:998-1003.

[40] Kristjanson LJ, Chalmers K, Woodgate R. Information and Support Needs of Adolescent Children of Women with Breast Cancer. Oncol Nurs Forum 2004;31:111-119.

[41] Lindholm L, Makela C, Rantanen-Siljamaki S, Nieminen A-L. The role of significant others in the care of women with breast cancer. Int J Nurs Pract 2007;13:173-181.

[42] Durity MB, Wyness A, Durity F, Ratel M. Education and information needs identified by patients and key family members prior to surgery for a skull base neoplasm: implications for practice. Axone 2000;22:32-45. [43] Janda M, Eakin E, Bailey L, Walker D, Troy K. Supportive care needs of people with brain tumours and their carers. Support Care Cancer 2006;14:1094-1103.

[44] Fukui S. Information Needs and the Related Characteristics of Japanese Family Caregivers of Newly Diagnosed Patients With Cancer. Cancer Nurs 2002;25:181-186.

[45] Soothill K, Morris SM, Harman JC, Francis B, Thomas C, McIllmurray MB. Informal carers of cancer patients: what are their unmet psychosocial needs? Health Soc Care Community 2001;9:464-475.

[46] Wilson K, Pateman B, Beaver K, Luker KA. Patient and carer needs following a cancer-related hospital admission: the importance of referral to the district nursing service. J Adv Nurs 2002;38:245-253. [47] Morris SM, Thomas C. The need to know: informal carers and information. Eur J Cancer Care (Engl) 2002;11:183-187. 
[48] Echlin KN, Rees CE. Information Needs and Information-seeking Behaviors of Men With Prostate Cancer and Their Partners: A Review of the Literature. Cancer Nurs 2002;25:35-41.

[49] Rees CE, Bath PA. The information needs and source preferences of women with breast cancer and their family members: a review of the literature published between 1988 and 1998. J Adv Nurs 2000;31:833-841. [50] Timmins F. Exploring the concept of 'information need'. Int J Nurs Pract 2006;12:375-381.

[51] Lazarus RS, Folkman S. Stress, appraisal and coping. New York: Springer; 1984.

[52] Kilpatrick MG, Kristjanson LJ, Tataryn DJ. Measuring the information needs of husbands of women with breast cancer: validity and reliability of the Family Inventory of Needs-Husbands. Oncol Nurs Forum 1998;25:1347-1351.

[53] National Cancer Action Team. NCAT Cancer Patient Information Pathways. 2009 [cited 200922 Jan]; Available from: http://www.mccn.nhs.uk/ncat

Appendix A: Example of search strategy: Strategy for MEDLINE search

\begin{tabular}{|l|l|l|}
\hline$\# 1$ & Exp neoplasms /(MeSH) & \\
\hline$\# 2$ & Cancer\$ in ti,ab & \\
\hline$\# 3$ & Tumor\$ in ti,ab & \\
\hline$\# 4$ & Tumour\$ in ti,ab & \\
\hline$\# 5$ & Neoplasm\$ in ti,ab & \\
\hline$\# 6$ & Malignan\$ in ti,ab & Cancer \\
\hline$\# 7$ & $\# 1$ or $\# 2$ or \#3 or \#4 or \#5 or \#6 & \\
\hline$\# 8$ & Exp family/(MeSH) & \\
\hline$\# 9$ & Exp family functioning/(MeSH) & \\
\hline$\# 10$ & Exp family coping/(MeSH) & \\
\hline$\# 11$ & Exp family illness/(MeSH) & \\
\hline$\# 12$ & Exp family relationships/(MeSH) & \\
\hline$\# 13$ & Mother\$ & \\
\hline$\# 14$ & Father\$ & \\
\hline$\# 15$ & Son & \\
\hline$\# 16$ & Sons & \\
\hline$\# 17$ & Daughter\$ & \\
\hline$\# 18$ & Step?mother\$ & \\
\hline$\# 19$ & Step?father\$ & \\
\hline$\# 20$ & Step?son\$ & \\
\hline
\end{tabular}




\begin{tabular}{|c|c|c|}
\hline$\# 21$ & Step?daughter\$ & \\
\hline$\# 22$ & Mother-in-law\$ & \\
\hline$\# 23$ & Father-in-law\$ & \\
\hline$\# 24$ & Son-in-law\$ & \\
\hline$\# 25$ & Daughter-in-law\$ & \\
\hline$\# 26$ & Grandfather\$ & \\
\hline \#27 & Grandmother\$ & \\
\hline$\# 28$ & Grandparent\$ & \\
\hline$\# 29$ & Husband\$ & \\
\hline$\# 30$ & Wife & \\
\hline$\# 31$ & Wives & \\
\hline$\# 32$ & Partner\$ & \\
\hline$\# 33$ & Spouse\$ & \\
\hline$\# 34$ & Family member\$ & \\
\hline$\# 35$ & Close relative\$ & \\
\hline$\# 36$ & Significant other\$ & \\
\hline$\# 37$ & In?law\$ & \\
\hline$\# 38$ & Step?family & \\
\hline \#39 & Step?families & \\
\hline$\# 40$ & Couple\$ & \\
\hline$\# 41$ & Exp Caregiver/ (MeSH) & \\
\hline$\# 42$ & $\begin{array}{l}\# 8 \text { or } \# 9 \text { or } \# 10 \text { or } \# 11 \text { or } \# 12 \text { or } \# 13 \text { or } \# 14 \\
\text { or } 15 \text { or } \# 16 \text { or } \# 17 \text { or } \# 18 \text { or } \# 19 \text { or } \# 20 \text { or } \\
\# 21 \text { or } \# 22 \text { or } \# 23 \text { or } \# 24 \text { or } \# 25 \text { or } \# 26 \text { or } \\
\# 27 \text { or } \# 28 \text { or } \# 29 \text { or } \# 30 \text { or } \# 31 \text { or } \# 32 \text { or } \\
\# 33 \text { or } \# 34 \text { or } \# 35 \text { or } \# 36 \text { or } \# 37 \text { or } \# 38 \text { or } \\
\# 39 \text { or } \# 40 \text { or } \# 41\end{array}$ & Family members \\
\hline$\# 43$ & Exp Health information/(MeSH) & \\
\hline$\# 44$ & Information need\$ & \\
\hline$\# 45$ & Information preference\$ & \\
\hline \#46 & $\# 43$ or $\# 44$ or $\# 45$ & Information needs \\
\hline$\# 47$ & $\# 7$ and $\# 42$ and $\# 46$ & $\begin{array}{l}\text { Information needs of family members of } \\
\text { people with cancer }\end{array}$ \\
\hline
\end{tabular}


Table 1. Sample characteristics ( $n=32$ articles)

\begin{tabular}{|c|c|c|}
\hline Characteristics & $\mathbf{N}$ & $\%^{1}$ \\
\hline \multicolumn{3}{|l|}{ Relationship to patient } \\
\hline Spouse/partner & 14 & 43.8 \\
\hline Children & 4 & 12.5 \\
\hline Mixed relationships & 14 & 43.8 \\
\hline \multicolumn{3}{|l|}{ Cancer sites } \\
\hline Breast & 12 & 37.5 \\
\hline Prostate & 7 & 21.9 \\
\hline Brain & 2 & 6.3 \\
\hline Colon & 1 & 3.1 \\
\hline Oesophageal & 1 & 3.1 \\
\hline Multiple sites & 7 & 21.9 \\
\hline Not specified & 2 & 6.3 \\
\hline \multicolumn{3}{|l|}{ Sample country } \\
\hline Canada & 10 & 31.3 \\
\hline US & 7 & 21.9 \\
\hline UK & 6 & 18.8 \\
\hline Australia & 3 & 9.4 \\
\hline Finland & 2 & 6.3 \\
\hline Japan & 1 & 3.1 \\
\hline Turkey & 1 & 3.1 \\
\hline Sweden & 1 & 3.1 \\
\hline Greece & 1 & 3.1 \\
\hline \multicolumn{3}{|c|}{ Cancer continuum phase - stage of patient at time of recruitment } \\
\hline Diagnosis/treatment & 14 & 43.8 \\
\hline Post-treatment/survivorship & 2 & 6.3 \\
\hline Multiple specific stages & 13 & 40.6 \\
\hline Not specified & 3 & 9.4 \\
\hline \multicolumn{3}{|l|}{ Cancer continuum phase - focus of study } \\
\hline Diagnosis/treatment & 23 & 71.9 \\
\hline Multiple specific stages & 4 & 12.5 \\
\hline Stages not specified & 5 & 15.6 \\
\hline \multicolumn{3}{|l|}{ Publication date } \\
\hline $1998-2002$ & 15 & 46.9 \\
\hline 2003- April2008 & 17 & 53.1 \\
\hline \multicolumn{3}{|l|}{ Overall study design } \\
\hline Concurrent & 16 & 50.0 \\
\hline Retrospective & 7 & 21.9 \\
\hline Prospective/longitudinal & 2 & 6.3 \\
\hline $\begin{array}{l}\text { Other (retrospective/ concurrent: 6; longitudinal/ } \\
\text { concurrent: 1) }\end{array}$ & 7 & 21.9 \\
\hline Quantitative (questionnaire/survey) & 15 & 46.9 \\
\hline Validated $\mathrm{Q}^{2}$ & 7 & 21.9 \\
\hline
\end{tabular}

\footnotetext{
${ }^{1}$ Rounded to the nearest full number.
} 


\begin{tabular}{|c|c|c|}
\hline Study-specific Q & 6 & 18.8 \\
\hline $\begin{array}{l}\text { Other (content analysis of helpline/message } \\
\text { boards) }\end{array}$ & 2 & 6.3 \\
\hline Qualitative & 11 & 31.3 \\
\hline Interviews & 7 & 21.9 \\
\hline Focus groups & 1 & 3.1 \\
\hline Interview + focus groups & 2 & 6.3 \\
\hline Questionnaire (with open-ended questions) & 1 & 3.1 \\
\hline Mixed methods & 6 & 15.6 \\
\hline Validated Q+ Interview + focus groups & 1 & 3.1 \\
\hline Validated Q+ interview/ open-ended questions & 3 & 9.4 \\
\hline Study-specific Q + interview & 2 & \\
\hline \multicolumn{3}{|l|}{ Sample size } \\
\hline Quantitative studies & $\begin{array}{l}\text { Range 16- } \\
26,789\end{array}$ & \\
\hline$>30$ & $5^{3}$ & \\
\hline $30-100$ & 9 & \\
\hline$>100$ & 3 & \\
\hline Qualitative studies & Range 9-31 & \\
\hline$<15$ & 3 & \\
\hline $15-40$ & 8 & \\
\hline$>40$ & 0 & \\
\hline Mixed methods studies & $\begin{array}{l}\text { Range 15- } \\
195\end{array}$ & \\
\hline$<30$ & 1 & \\
\hline $30-100$ & 5 & \\
\hline$>100$ & 1 & \\
\hline
\end{tabular}

\footnotetext{
${ }^{2}$ This denotes the method by which information about information needs specifically was collected, not the data collection method overall.

${ }^{3}$ Two studies had two groups of participants. Each of these was here included as a separate group of participants, hence the total number of studies in this section is greater than the actual number of studies.
} 
Table 2. Typology of the information needs of partners and family members of cancer patients ( $n=32$ articles)

Quantitative articles $=$ normal font

Qualitative articles =underlined font

Mixed methods articles $=$ bold font

\begin{tabular}{|c|c|c|c|}
\hline Category & Subcategory & References for sub-category (listed) & $\begin{array}{l}\text { Total references for } \\
\text { category ( } n, \% \text { of all } \\
\text { articles) }\end{array}$ \\
\hline \multirow{9}{*}{$\begin{array}{l}\text { Treatment- } \\
\text { related } \\
\text { information }\end{array}$} & Side effects of treatment & $\begin{array}{l}1,2,3, \underline{4}, 6,7,8,11,12,13,14,15,17,18,20,2 \\
1,22,23,24, \underline{25,26,28, \underline{30,31,32}}\end{array}$ & \multirow[t]{9}{*}{$29(90.6 \%)$} \\
\hline & $\begin{array}{l}\text { General treatment-related information } \\
\text { (not further specified) }\end{array}$ & $\begin{array}{l}1,2,3,4,6,7, \overline{9,10,11}, 12,14,17,20,22,23,2 \\
4,25,27,28,30\end{array}$ & \\
\hline & Nutrition & $1,3,8, \underline{10}, 14,15,17, \underline{25}, 31,32$ & \\
\hline & $\begin{array}{l}\text { Practical Aspects of treatment } \\
\text { (e.g. waiting lists, location, urgency, } \\
\text { duration, problems with taking } \\
\text { medication, treatment plans) }\end{array}$ & $1,2,8, \underline{9,11}, 17, \underline{18}, 31$ & \\
\hline & Treatment options & $1,3,8, \underline{9,16}, 28$ & \\
\hline & Complementary/alternative therapies & $3,8,11,16,20,21,28$ & \\
\hline & Medication & $1,3, \overline{9,15,31}$ & \\
\hline & $\begin{array}{l}\text { Surgical and other procedures (e.g. } \\
\text { colonoscopy) }\end{array}$ & $7,10, \underline{25}$ & \\
\hline & Understanding trials & 3,28 & \\
\hline \multirow{7}{*}{$\begin{array}{l}\text { Diagnosis- / } \\
\text { Prognosis- } \\
\text { related } \\
\text { information }\end{array}$} & General development of illness/prognosis & $\begin{array}{l}1,3,6,8, \underline{9,10,11}, 12,17,19, \underline{21} \\
22,23,24, \underline{25}, 29, \underline{30}, 31,32\end{array}$ & \multirow[t]{7}{*}{$26(81.3 \%)$} \\
\hline & Spread of disease/stage & $1,3,6,7,8, \underline{9,10}, 12,14,15,20,21$ & \\
\hline & Diagnostic tests & $1,2,7,17, \underline{25,28}$ & \\
\hline & Remission/recurrence/metastatic disease & $1,2,8, \underline{9,10}, 25$ & \\
\hline & Be informed of changes in condition & $19,22,23,24,27$ & \\
\hline & Chances of survival & $9,10,11,20$ & \\
\hline & Reasons for delay in diagnosis & 7 & \\
\hline \multirow[t]{3}{*}{$\begin{array}{l}\text { Coping } \\
\text { information }\end{array}$} & $\begin{array}{l}\text { Dealing with psychological impact on } \\
\text { patient }\end{array}$ & $2,12,13,15,17,20,21,22,23,24,27,28,29$ & \multirow[t]{3}{*}{$22(68.8 \%)$} \\
\hline & Dealing with own emotions & $1, \underline{4}, \underline{9,10}, 13,15, \underline{18}, \underline{30}$ & \\
\hline & Living with uncertainty & $3,10,15, \underline{18}, 22,24, \overline{25}$ & \\
\hline
\end{tabular}




\begin{tabular}{|c|c|c|c|}
\hline Category & Subcategory & References for sub-category (listed) & $\begin{array}{l}\text { Total references for } \\
\text { category ( } \mathrm{n}, \% \text { of all } \\
\text { articles) }\end{array}$ \\
\hline & $\begin{array}{l}\text { Help to cope with stress (own and } \\
\text { patient's) and general well-being }\end{array}$ & $2, \underline{10,26}, 28,29$ & \\
\hline \multirow[t]{5}{*}{$\begin{array}{l}\text { Information on } \\
\text { self- } \\
\text { care/homecare }\end{array}$} & $\begin{array}{l}\text { Self-care/homecare } \\
\text { (for instance, things like catheter care or } \\
\text { colostomy care) }\end{array}$ & $\begin{array}{l}1,3,4,6,8,13,19,20,22,23,24, \underline{25}, \underline{26}, 27, \underline{30} \\
, 32\end{array}$ & \multirow[t]{5}{*}{$21(65.6 \%)$} \\
\hline & Help to optimise patient's comfort & $2,12,15$ & \\
\hline & Help maintain patient's independence & 15 & \\
\hline & $\begin{array}{l}\text { Information on the availability of care } \\
\text { services }\end{array}$ & 7 & \\
\hline & How to deal with an emergency & 17 & \\
\hline \multirow{5}{*}{$\begin{array}{l}\text { Cancer-specific } \\
\text { information }\end{array}$} & Understanding cancer/ terminology & $1,2,7,8, \underline{9}, 10,11,16,18,20,21, \underline{26}, 32$ & \multirow[t]{5}{*}{$20(62.5 \%)$} \\
\hline & Symptoms & $1,7,21,22,23,24,27$ & \\
\hline & Causes and risk factors & $2,3, \underline{5}, 6,8, \underline{9}, 11,20,28$ & \\
\hline & Incidence rates & $\underline{9}$ & \\
\hline & Screening & 28 & \\
\hline \multirow{6}{*}{$\begin{array}{l}\text { Information } \\
\text { about impact } \\
\text { on the family }\end{array}$} & Restrictions on activities & $2,3, \underline{4}, 6,8,17,22,23,24,27, \underline{30}$ & \multirow{6}{*}{$19(59.4 \%)$} \\
\hline & Psychosocial impact on family (general) & $1,2,3, \underline{5}, 6,12,19$ & \\
\hline & $\begin{array}{l}\text { Communicating about the illness within } \\
\text { the family }\end{array}$ & $2,13,15,20,22,23,24,27, \underline{30}$ & \\
\hline & Impact on social life & $2,3,6,8,10,15$ & \\
\hline & Impact on everyday life & 29 & \\
\hline & Role changes & 15 & \\
\hline \multirow[t]{2}{*}{$\begin{array}{l}\text { Information on } \\
\text { support }\end{array}$} & $\begin{array}{l}\text { Availability of social support, support } \\
\text { groups and programmes, and community } \\
\text { resources }\end{array}$ & $\begin{array}{l}1,2,4,5,8,10,13,15,21,22,23,24, \underline{25}, 27,28 \\
, 30,31,32\end{array}$ & \multirow[t]{2}{*}{$18(56.3 \%)$} \\
\hline & Spiritual support & $1,15,28$ & \\
\hline \multirow{5}{*}{$\begin{array}{l}\text { Information } \\
\text { about impact } \\
\text { on relationship } \\
\text { with partner }\end{array}$} & Sexuality & $1,2,3,4,6,8,13,14,15,19,22,23,24,27$ & \multirow[t]{5}{*}{$16(50.0 \%)$} \\
\hline & General impact on partner relationships & $4,9,13,15, \underline{25}$ & \\
\hline & Intimacy & $\overline{19}, 22,23, \overline{24}, 27$ & \\
\hline & Body image & 8 & \\
\hline & Fertility & 8 & \\
\hline $\begin{array}{l}\text { Information on } \\
\text { practical issues }\end{array}$ & $\begin{array}{l}\text { Practical impact/available resources (i.e. } \\
\text { financial, household) }\end{array}$ & $2, \underline{4}, 8,15, \underline{18}, 20,22,23,24,27,28, \underline{30}$ & $13(40.6 \%)$ \\
\hline
\end{tabular}




\begin{tabular}{|c|c|c|c|}
\hline Category & Subcategory & References for sub-category (listed) & $\begin{array}{l}\text { Total references for } \\
\text { category ( } \mathrm{n}, \% \text { of all } \\
\text { articles) }\end{array}$ \\
\hline & Transport & 8,25 & \\
\hline & Duration of sick leave & 2 & \\
\hline & Legal services & 18 & \\
\hline & Settling affairs/will & 18 & \\
\hline \multirow{5}{*}{$\begin{array}{l}\text { information on } \\
\text { hospital care }\end{array}$} & Be informed of changes in care & $22,23,24,27$ & \multirow[t]{5}{*}{$9(28.1 \%)$} \\
\hline & $\begin{array}{l}\text { Information about who is the designated } \\
\text { staff/physician who is medically } \\
\text { responsible }\end{array}$ & $1,2, \underline{16}$ & \\
\hline & Info on hospital operational procedures & 7 & \\
\hline & $\begin{array}{l}\text { Info on various kinds of help help/support } \\
\text { HCP can offer }\end{array}$ & 1 & \\
\hline & Referrals to medical services & 28 & \\
\hline \multirow{3}{*}{$\begin{array}{l}\text { Follow- } \\
\text { up/rehabilitatio } \\
\mathrm{n} \text { information }\end{array}$} & Post-surgical info/support & 7,10 & \multirow[t]{3}{*}{$5(15.6 \%)$} \\
\hline & Continuing contact after discharge & 1,25 & \\
\hline & Follow-up info from hospital & 1,8 & \\
\hline
\end{tabular}

